\title{
Downregulation of microRNA-448 improves isoflurane-induced learning and memory impairment in rats
}

\author{
QUN WU $^{1}$, QINXUE DAI ${ }^{1}$, LIUMING JIANG ${ }^{1}$, YICHUAN WANG ${ }^{1}$, \\ TAO YANG ${ }^{1}$, JIANXIA MIAO ${ }^{1}$, JUNLU WANG ${ }^{1}$ and YU HAN ${ }^{2}$ \\ ${ }^{1}$ Department of Anesthesiology; ${ }^{2}$ Laparoscopic Surgical Center and Sino-American Minimally Invasive Surgical Center, \\ The First Affiliated Hospital, Wenzhou Medical University, Wenzhou, Zhejiang 325000, P.R. China
}

Received April 22, 2016; Accepted March 24, 2017

DOI: $10.3892 / \mathrm{mmr} .2017 .6724$

\begin{abstract}
The present study aimed to investigate the potential role of microRNA-448 (miR-448) in isoflurane-induced learning and memory impairment in rats. Sprague-Dawley rats were used for the construction of isoflurane-treated models. The Morris water maze test was used to evaluate the effects of isoflurane on rats regarding the following parameters: Swimming speed, escape latency and time in original quadrant. Influences of isoflurane on neuron apoptosis and miR-448 expression in rat hippocampus tissue were analyzed by flow cytometry and reverse transcription-quantitative polymerase chain reaction, respectively. Furthermore, the effects of miR-448 on the expression of cell apoptosis-associated proteins were investigated by flow cytometry. The results demonstrated that isoflurane treatment induced higher escape latency and lower time spent in original quadrant compared with the control rats. In addition, isoflurane treatment induced neuron apoptosis and miR-448 was highly expressed in the hippocampal tissue of isoflurane-treated rats. Furthermore, Bcl-x was significantly downregulated while caspase-3 expression was upregulated by an miR-448 inhibitor. Combined the results of the current study indicate that miR-448 knockdown may have pivotal roles in improving isoflurane-induced learning and memory impairment via suppressing neuron apoptosis.
\end{abstract}

\section{Introduction}

It has been previously reported that the combination of several kinds of anesthesia may damage brain function (1), and accumulating studies have reported impairment in learning

Correspondence to: Dr Yu Han, Laparoscopic Surgical Center and Sino-American Minimally Invasive Surgical Center, The First Affiliated Hospital, Wenzhou Medical University, 2 FuXue Xiang, Jiefang Street, Wenzhou, Zhejiang 325000, P.R. China

E-mail: hanyu03586@126.com

Key words: learning and memory impairment, microRNA-448, isoflurane, cell apoptosis or memory following anesthesia (2-4). Studies indicate that impairments caused by anesthesia application performed on brain neurons were observed in various types of animals, including mammals $(5,6)$, and indicated that general anesthesia exhibits an age-dependent effect on the brain (7).

As a common inhaled general anesthetic, isoflurane is considered to contribute to long-term memory deficit (8). For example, isoflurane application induced neuron apoptosis in a dose-dependent manner in 7-day-old rats, and the co-application of isoflurane, imidazole valium and nitrous oxide further increased apoptosis (9). Stratmann et al (10) reported that isoflurane application induced neuron apoptosis and cognitive impairment following 8 months of isoflurane treatment in rats. Due to the importance of potential anesthesia-induced neuron damage and the complex mechanism of action, an increasing number of studies have focused on investigating the mechanisms behind these effects (11-13).

microRNAs (miRNAs) are endogenous non-coding RNAs that are 20-22 nucleotides in length and function in various biological processes at the transcriptional or post-transcriptional level by targeting the 3'-untranslated regions of genes (14). Studies have indicated important roles for certain miRNAs in the pathology of anesthesia-induced neuron damage. McAdams et al (15) screened 9 differentially expressed miRNAs, including miR-204-5p, miR-455-3p, miR-448-5p and miR-574-3p, in the hippocampal tissue of morphine-exposed mice. Additionally, Luo et al (16) reported that the knockdown of let-7d acts as a contributor for isoflurane-induced learning and memory impairment. The roles of miR-448 in cell apoptosis in various diseases have also been reported $(17,18)$, however, to the best of our knowledge, this has not previously been investigated in isoflurane-induced learning and memory impairment.

In the current study, miR-448 expression in isoflurane-treated rats was detected and the effects of miR-448 expression on learning and memory in the hippocampal tissue of isoflurane-treated rats were investigated by downregulating the expression of miR-448. The present study aimed to investigate the potential mechanism underlying the effect of miR-448 on learning and memory impairment in isoflurane-treated rats. The present study may provide a theoretical basis for the molecular mechanism of isoflurane in clinical treatment of neuron damage. 


\section{Materials and methods}

Model construction. The procedure was approved by the local committee of The First Affiliated Hospital, Wenzhou Medical University (Zhejiang 325000, P.R. China) and all animals were treated according to the Guide for the Care and Use of Laboratory Animals of the Institute for Laboratory Animal Research (19). Sprague-Dawley male rats ( $n=32$; age, 18 months; weight, 450-550 g) were obtained from the Institute of Experimental Animals of the Medical Scientific Academy in Wenzhou Medical University (Wenzhou, China). The rats were housed in a standard animal-grade room with free access to standard rodent pellet diet and water. The temperature was maintained at $23 \pm 2^{\circ} \mathrm{C}$, the relative humidity was $55 \pm 10 \%$ and a 12 h:12 h light:dark cycle. Following 1 week acclimation period in the laboratory, rats were randomly assigned to two groups; The control group and anesthesia group $(n=16$ per group). The experimental rats were exposed to $2 \%$ isoflurane (Baxter, Deerfield, IL, USA) for $4 \mathrm{~h}$, whereas rats in the control group received air/oxygen at identical flow rates $(0.7 \mathrm{l} / \mathrm{min})$ in identical chambers. The rats were used for the experiments immediately after the anesthesia. Isoflurane concentration in the chamber was monitored with a vaporizer. The rectal temperature was maintained at $37.0 \pm 0.5^{\circ} \mathrm{C}$. All rats were visually inspected for respiratory effort and skin color. Pulse oximeter oxygen saturation was routinely monitored during anesthesia. Mean arterial blood pressure was recorded using non-invasive sphygmomanometers.

Morris water maze test. Cognitive function was analyzed between 9 am and 3 pm using the Morris water maze test system, as previously described (20). Briefly, the maze (depth, $80 \mathrm{~cm}$; diameter, $100 \mathrm{~cm}$ ) was separated into four quadrants of equal size on the monitor screen of a computer, and was filled to a depth of $30 \mathrm{~cm}$ with water. The temperature of the water was maintained at $24 \pm 0.5^{\circ} \mathrm{C}$. Swimming paths of rats were recorded using a video camera and analyzed with VideoMot software version 2.4.50923 (TSE Systems GmbH, Bad Homburg, Germany) regarding the following parameters: Swimming speed, escape latency and time in original quadrant. The test was conducted on 4 consecutive days to observe escape latency and time spent in the quadrant of rats in the Morris water maze. Rats were placed in the maze from four random points of the tank and were allowed to search for the platform for $2 \mathrm{~min}$. If this was not achieved, the rat was gently placed on the platform and left for $20 \mathrm{sec}$.

Reverse transcription-quantitative polymerase chain reaction (RT-qPCR). Total RNA was isolated using TRIzol reagent (Invitrogen; Thermo Fisher Scientific, Inc., Waltham, MA, USA) as previously described (21), and was treated with RQ1 RNase-free DNase I (Promega Corporation, Madison, WI, USA). The concentration and purity of the isolated RNA were measured with SMA 400 UV-VIS (Merinton, Shanghai, China). Purified RNA $(0.5 \mu \mathrm{g} / \mu \mathrm{l})$ with nuclease-free water was used for cDNA synthesis with the PrimeScript 1st Strand cDNA Synthesis kit (6110A; Biotechnology Co., Ltd., Dalian, China) according to the manufacturer's protocol. Target gene expression was detected in an Eppendorf Mastercycler (Eppendorf, Hamburg, Germany) using the SYBR ExScript
RT-PCR kit (DRR053S; Takara Biotechnology Co., Ltd.). PCR was run under the following parameters: Initial denaturation cycle of $1 \mathrm{~min}$ at $95^{\circ} \mathrm{C}, 35$ cycles of denaturation at $94^{\circ} \mathrm{C}$ for $30 \mathrm{sec}$, annealing at $60^{\circ} \mathrm{C}$ for $30 \mathrm{sec}$, extension at $72^{\circ} \mathrm{C}$ for $2 \mathrm{~min}$ and a final extension at $72^{\circ} \mathrm{C}$ for $7 \mathrm{~min}$. MiR expression was quantified by the comparative $2^{-(\Delta \Delta \mathrm{Cq})}$ method and normalized to U6 expression (22). The primers for miR-448 were: Forward: 5'-TTATTGCGATGTGTTCCTTATG-3', Reverse primer: 5'-ATGCATGCCACGGGCATATACACT-3'; and U6 were: Forward: 5'-CTCGCTTCGGCAGCACA-3' Reverse: 5'-AACGCTTCACGAATTTGCGT-3'. Experiments were performed at least three times.

Cell culture and cell transfection. Hippocampal cultures were prepared as described previously (23). Briefly, the tissue was dissected and digested in $2 \mathrm{ml}$ of $2 \mathrm{mg} / \mathrm{ml}$ papain for $30 \mathrm{~min}$ at $37^{\circ} \mathrm{C}$ and was subsequently inactivated with $10 \%$ fetal bovine serum (FBS; Gibco; Thermo Fisher Scientific, Inc.). The tissue was triturated by a pipette and was passed through a cell strainer to remove undissociated tissue. Cells were subsequently centrifuged at $400 \mathrm{x} \mathrm{g}$ for $5 \mathrm{~min}$ at $4^{\circ} \mathrm{C}$. The supernatant was discarded and the cell pellet was resuspended in Dulbecco's modified Eagle's medium (DMEM; Sigma-Aldrich; Merck KGaA, Darmstadt, Germany) containing $1 \mathrm{X}$ antibiotics (penicillin-streptomycin) and 5\% FBS. Cells were plated on poly-L-lysine (Invitrogen; Thermo Fisher Scientific, Inc.) coated plates or coverslips at a density of $1 \times 10^{5}$ cells $/ \mathrm{ml}$. The medium was replaced by Neurobasal medium (Invitrogen; Thermo Fisher Scientific, Inc.) with 2\% B27 (Sigma-Aldrich; Merck $\mathrm{KGaA}$ ) after plating overnight at $37^{\circ} \mathrm{C}$ in a $5 \% \mathrm{CO}_{2}$ incubator. For cell transfection, miR-448 inhibitor $(150 \mathrm{nM}$; Sangon Biotech Co., Ltd., Shanghai, China) was transfected into hippocampal cells for $24 \mathrm{~h}$ at $37^{\circ} \mathrm{C}$ with Lipofectamine 2000 (Invitrogen; Thermo Fisher Scientific, Inc.) according to the manufacturer's protocol. To produce stable miR-448-depleted transfectants, miR-448 inhibitor sequences were amplified from miRZip-448 construct (System Biosciences, Palo Alto, CA, USA) and subcloned into pSilencer4.1 polyclone sites with HindIII and BamHI sites. The miR-448 inhibitor sequence was 5'-AUGGGACAUCCUACAUAUGCAA-3' and the scramble RNA sequence was 5'-CUAAGUCUUGGUAGUCACGUU C-3'. Cells transfected with the scramble RNA (150 nM) or without any transfection were considered as the control.

Western blotting. After $4 \mathrm{~h}$ of treatment with mock or isoflurane, the rats were sacrificed and total protein was extracted from the tissue using 1X RIPA buffer (89900; Piece; Thermo Fisher Scientific, Inc.). Cells were lysed with radioimmunoprecipitation assay buffer (Sangon Biotech Co., Ltd., Shanghai, China) containing phenylmethanesulfonyl fluoride (Sigma-Aldrich; Merck KGaA) and the lysates were centrifuged at $6,400 \mathrm{x}$ g for $10 \mathrm{~min}$ at $4^{\circ} \mathrm{C}$. The supernatants were collected and the protein concentration was determined using a Pierce $^{\mathrm{TM}}$ BCA Protein Assay kit (23227; Pierce; Thermo Fisher Scientific, Inc.). The proteins (20 $\mu \mathrm{g}$ per lane) were separated by $10 \%$ SDS-PAGE followed by transfer onto a polyvinylidene fluoride (PVDF) membrane (24). The membranes were blocked in 1\% TBS-Tween-20 (TBST) containing 5\% non-fat milk for $1 \mathrm{~h}$ at room temperature and then incubated with rabbit anti-rat antibodies against microtubule-associated protein tau 

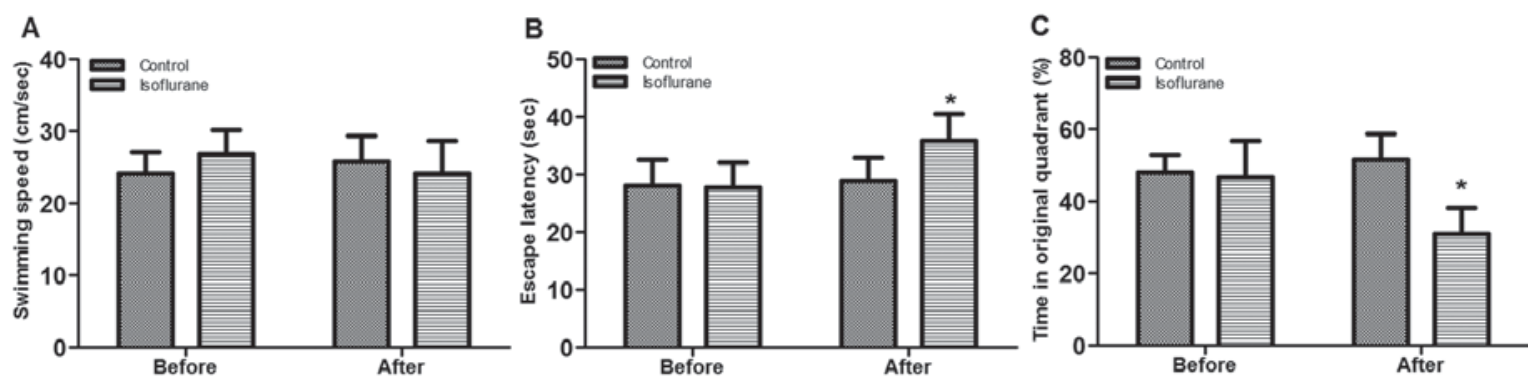

Figure 1. Morris water maze test for isoflurane-treated and control rats. Before rats were exposed to isoflurane, no significant difference was observed for the Morris water maze test parameters regarding the swimming speed, escape latency and time in original quadrant. (A) No significant difference was observed for the swimming speed for rats treated with or without isoflurane. (B) Escape latency for isoflurane-treated rats was significantly increased compared with the control rats. (C) Time spent in original quadrant for the isoflurane-treated rats was significantly reduced compared with the control rats. ${ }^{*} \mathrm{P}<0.05 \mathrm{vs.}$ control after treatment.
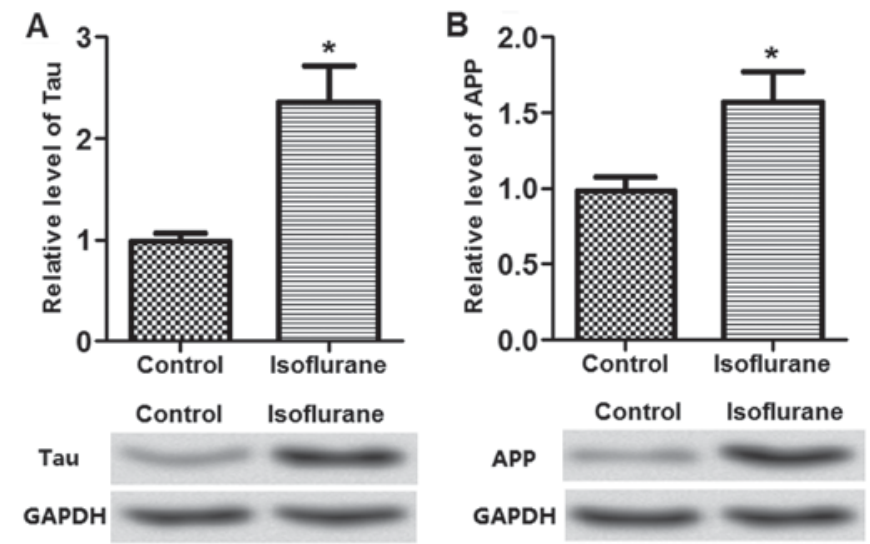

Figure 2. Detection of the expression of cell apoptosis-associated proteins in the hippocampus tissue. (A) Tau expression was upregulated by isoflurane treatment compared with controls. (B) APP expression was upregulated by isoflurane treatment compared with the control. ${ }^{*} \mathrm{P}<0.05$ vs. control. Tau, microtubule-associated protein tau; APP, amyloid- $\beta$ precursor protein.

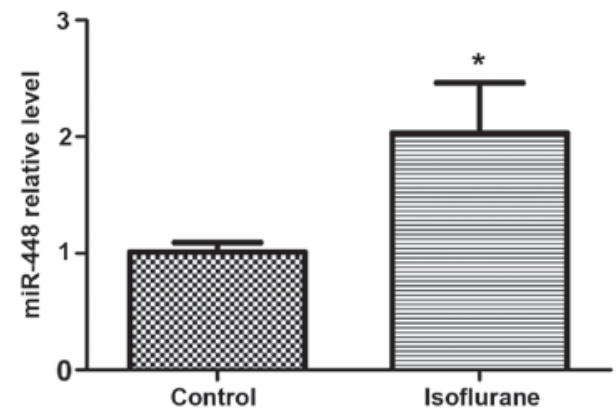

Figure 3. Expression of miR-448 in the isoflurane-treated hippocampus tissue. Compared with the control, the relative miR-448 expression was significantly increased by isoflurane treatment. ${ }^{*} \mathrm{P}<0.05$ vs. control. miR, microRNA.

(Tau; 44-734G), amyloid- $\beta$ precursor protein (APP; PA1-072), Bcl-x (PA5-21676), and caspase-3 (PA5-16335) at a 1:100 dilution (all from Invitrogen; Thermo Fisher Scientific, Inc.) overnight at $4^{\circ} \mathrm{C}$. Subsequently, the membranes were incubated with a horseradish peroxidase-conjugated goat anti-rabbit secondary antibody (PA1-27236; 1:1,000; Invitrogen; Thermo Fisher Scientific, Inc.) for $1 \mathrm{~h}$ at room temperature. Finally, the PVDF membranes were washed 3 times with 1X TBST

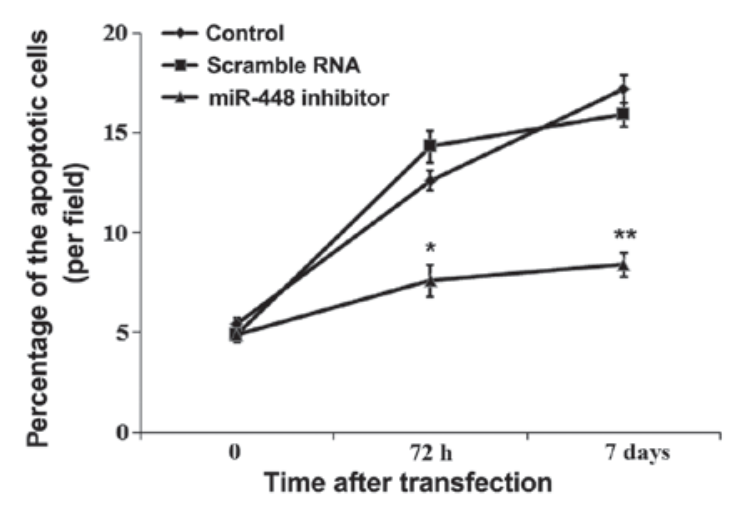

Figure 4. Effect of miR-448 expression on neuron apoptosis. No significant difference was observed for the apoptosis of neurons between the control and the scramble RNA-transfected cells. Untransfected cells were considered as the control. Compared with the control or scrambled group, neuron apoptosis was significantly suppressed by the miR-448 inhibitor after $72 \mathrm{~h}$ of transfection. ${ }^{*} \mathrm{P}<0.05$ and $^{* *} \mathrm{P}<0.01$ vs. control or scrambled group. miR, microRNA.

buffer for 10 min each. The signals were detected after the membranes were incubated with a chromogenic substrate using the enhanced chemiluminescence western blotting substrate (Pierce; Thermo Fisher Scientific, Inc.) according to the manufacturer's protocol. GAPDH (MA5-15738-BTIN; 1:1,000; Invitrogen; Thermo Fisher Scientific, Inc.) served as the internal control. The intensity of protein bands was quantified by densitometry using ImageJ software version 1.46 (National Institutes of Health, Bethesda, MD, USA).

Cell apoptosis assay. After $36 \mathrm{~h}$ of transfection, cells were incubated with the replacement of fresh cell culture medium containing serum-free medium. The cell apoptosis was analyzed by using the Annexin V-FITC Fluorescence Microscopy kit kit (550911; BD Biosciences, San Jose, CA, USA). Total cells were harvested, fixed with $3.7 \%$ formaldehyde for $15 \mathrm{~min}$ at room temperature, permeabilized with $0.1 \%$ Triton X-100 for 5 min at $37^{\circ} \mathrm{C}$, and washed three times with PBS buffer, cells were then resuspended in the 1XBinding Buffer. Subsequently, $5 \mu 1$ Annexin V-fluorescein isothiocyanate and $5 \mu \mathrm{l}$ propidium iodide were mixed with the cells. Following culture at room temperature for $10 \mathrm{~min}$, mixtures were analyzed using a FACScan flow cytometer (BD Biosciences). Annexin V-positive and propidium iodide-negative cells were considered to be apoptotic cells. 
A

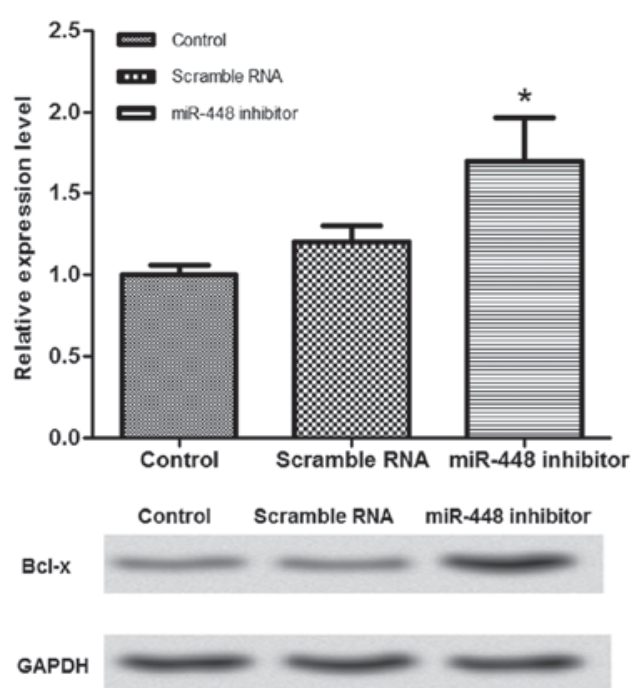

B

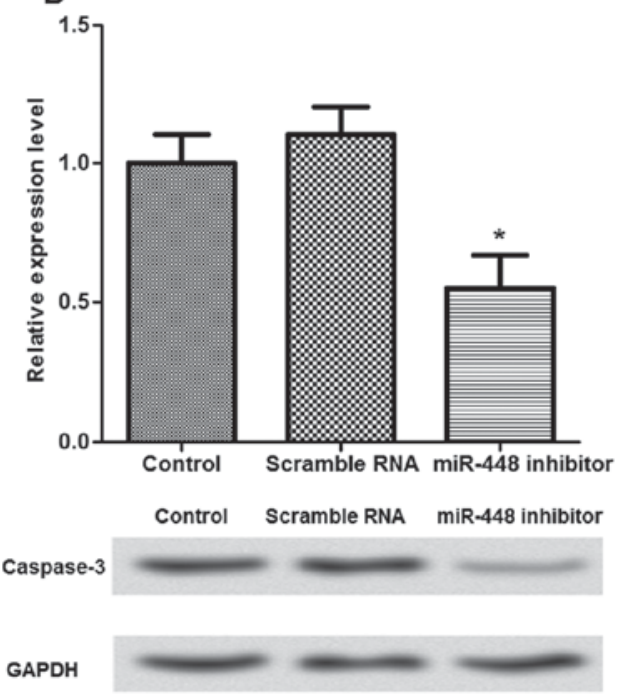

Figure 5. Effects of miR-448 on the expression of cell apoptosis-associated proteins. (A) Bcl-x expression was significantly increased by the knockdown of miR-448. (B) Caspase-3 protein was significantly decreased by the miR-448 inhibitor. Untransfected cells were considered as control group. "P $<0.05$ vs. control or scrambled group. miR, microRNA.

Statistical analysis. All experiments were performed independently three times. Data are presented as the mean \pm standard deviation. Data were calculated using GraphPad Prism version 5.0 (GraphPad Software, Inc., La Jolla, CA, USA). Significant differences among groups were analyzed using one-way analysis of variance followed by Tukey-Kramer's Post-hoc test. $\mathrm{P}<0.05$ was considered to indicate a statistically significant difference.

\section{Results}

Morris water maze test. Morris water maze test was conducted to assess the indexes for rats regarding the swimming speed, escape latency and time in original quadrant pre- and post-anesthesia (Fig. 1). The results demonstrated that no significant difference was observed for swimming speed between the control and anesthetic rats either prior or subsequent to anesthesia (Fig. 1A). However, the escape latency was significantly increased by isoflurane treatment $(\mathrm{P}<0.05$; Fig. 1B), whereas the time in original quadrant was significantly reduced in the isoflurane group compared with the control $(\mathrm{P}<0.05$; Fig. $1 \mathrm{C})$, indicating that the isoflurane treatment may impair learning and memory in rats.

Expression of apoptotic proteins in isoflurane-treated neurons. The dementia-associated neuron apoptotic proteins in the tissues, including Tau and APP, were measured to determine the effects of isoflurane on neuron apoptosis. The results demonstrated that Tau and APP expression were significantly upregulated by the isoflurane treatment (Fig. 2), indicating that isoflurane treatment may be associated with neuron cell apoptosis.

Expression of miR-448 in isoflurane-treated hippocampus tissues. Following isoflurane treatment, the rat hippocampus was isolated for the detection of miR-448 expression. The results demonstrated that the relative miR-448 expression level was significantly increased in the isoflurane-treated hippocampus compared with control rats (Fig. 3), which indicates that miR-448 expression may be associated with impaired learning and memory caused by isoflurane treatment in rats.

miR-448 induced hippocampus neuron apoptosis. The influence of miR-448 on neuron apoptosis was detected in the hippocampus of rats (Fig. 4). The percentage of apoptotic neurons was significantly decreased by miR-448 inhibitor transfection compared with controls $(\mathrm{P}<0.05)$.

Effects of miR-448 expression on the expression of cell apoptosis-associated proteins. The expression of cell apoptosis-associated proteins was measured to investigate the potential mechanism for miR-448 in neuron apoptosis (Fig. 5). When miR-448 expression was suppressed in the neurons, the relative protein expression of Bcl-x was significantly increased, while caspase-3 was significantly decreased $(\mathrm{P}<0.05)$, compared with the untransfected cells.

\section{Discussion}

Interest in the effect of general anesthetic on long-term memory is on the increase. The effect of anesthesia, including isoflurane, on learning and memory has been previously reported (25-27), however, a full understanding of the underlying mechanism remains to be elucidated. Additionally, previous studies have demonstrated that neuron apoptosis may be one of most important mechanisms involved in anesthesia-induced brain damage $(28,29)$, however, the mechanism remains to be established. The present study analyzed the expression of miR-448 in the hippocampal tissue of isoflurane-treated rats and investigated the effect of miR-448 expression on learning and memory impairment using the knockdown method. Consistent with previous reports $(30,31)$, isoflurane treatment induced learning and memory damage, which was indicated by increased escape latency and reduced 
time spent in original quadrant during the Morris water maze test (Fig. 1).

Subsequently, the present study detected the expression of cell apoptosis markers, including Tau and APP, in isoflurane-treated rats and the results demonstrated that Tau and APP levels were highly expressed in the isoflurane-treated rats (Fig. 2). Tau protein is a microtubule-associated protein that is expressed abundantly in neuronal axons (32), whereas APP protein functions as a cell surface receptor and performs physiological functions on the surface of neurons relevant to neurite growth, neuronal adhesion and axonogenesis (33). Li et al (34) demonstrated that Tau protein level was significantly increased by isoflurane treatment in cognitive dysfunction in transgenic APP695 mice. Similar results for APP were observed in transgenic mice in a study conducted by Zhang et al (35). Based on the results of the current study, it was hypothesized that isoflurane treatment impaired learning and memory in rats.

Meanwhile, the present study analyzed the expression of miR-448 in the hippocampal tissue of isoflurane-treated rats and the results demonstrated that miR-448 was upregulated following isoflurane treatment in rats (Fig. 3). Pivotal roles for miRNAs have been identified in various diseases, including cancer and cardiovascular diseases, via involvement in biological processes such as cell apoptosis $(36,37)$. Additionally, the results of the current study demonstrated that neuron apoptosis was significantly suppressed by miR-448 inhibitor application (Fig. 4), indicating that miR-448 may have certain roles in isoflurane-induced learning and memory damage via cell apoptosis. Consequently, the present study further measured the expression of cell apoptosis-associated proteins in vitro. It is suggested that $\mathrm{Bcl}-\mathrm{x}$ is a bcl-2 family member that is involved in the regulation of apoptosis (38), while caspase-3 is an apoptotic executor in various diseases (39). The association between miR-448 and caspase-3 in neuron apoptosis caused by isoflurane remains to be fully elucidated. However, Noh et al (40) demonstrated that caspase-3 was highly expressed following miR-448 overexpression in mice with Alzheimer's disease. In the present study, caspase-3 protein was downregulated while $\mathrm{Bcl}-\mathrm{x}$ was upregulated by the miR-448 inhibitor in isoflurane-treated neurons (Fig. 5), indicating that miR-448 downregulation may block neuron apoptosis via reducing caspase-3 and increasing Bcl-x expression.

In conclusion, the results presented in the present study indicate that miR-448 downregulation may contribute to improving the learning and memory impairment induced by isoflurane application by suppressing neuron apoptosis. The current study may provide a theoretical basis for the investigation of the mechanism underlying the effect of isoflurane on memory. Further experimental studies are required to investigate the underlying mechanism in depth and to explore the effects of isoflurane treatment on learning and memory.

\section{References}

1. Young C, Jevtovic-Todorovic V, Qin YQ, Tenkova T, Wang H, Labruyere J and Olney JW: Potential of ketamine and midazolam, individually or in combination, to induce apoptotic neurodegeneration in the infant mouse brain. Br J Pharmacol 146: 189-197, 2005

2. Smith RA: Enhancement of impaired motor and mental functions, using dextromethorphan and oxidase enzyme inhibitor. US Patent US20070191411 A1. Filed October 7, 2005; issued August 16, 2007
3. Bolger C, Arms SW, Townsend CP and Smith KR: Method and apparatus for monitoring eye tremor. US Patent US 8500282 B2. Filed September 22, 2011; issued August 6, 2013.

4. Rahaghi F and Botero J: Endotracheal tube apparatus and method for use. US 20070221229 A1. Filed 25 October 2006; issued September 272007

5. Jevtovic-Todorovic V, Hartman RE, Izumi Y, Benshoff ND, Dikranian K, Zorumski CF, Olney JW and Wozniak DF: Early exposure to common anesthetic agents causes widespread neurodegeneration in the developing rat brain and persistent learning deficits. J Neurosci 23: 876-882, 2003.

6. Olney JW, Tenkova T, Dikranian K, Qin YQ, Labruyere J and Ikonomidou C: Ethanol-induced apoptotic neurodegeneration in the developing C57BL/6 mouse brain. Brain Res Dev Brain Res 133: 115-126, 2002.

7. Viberg H, Pontén E, Eriksson P, Gordh T and Fredriksson A Neonatal ketamine exposure results in changes in biochemical substrates of neuronal growth and synaptogenesis, and alters adult behavior irreversibly. Toxicology 249: 153-159, 2008.

8. Ballesteros KA, Sikorski A, Orfila JE and Martinez JL Jr: Effects of inhaled anesthetic isoflurane on long-term potentiation of CA3 pyramidal cell afferents in vivo. Int J Gen Med 5: 935-942, 2012

9. Johnson SA, Chainllie Y and Olney JW: Isoflurane-induced neuroapoptosis in the developing brain of nonhypoglycemic mice. J Neurosurg Anesthesiol 20: 21-28, 2008.

10. Stratmann G, Sall JW, May LD, Bell JS, Magnusson KR, Rau V, Visrodia KH, Alvi RS, Ku B, Lee MT and Dai R: Isoflurane differentially affects neurogenesis and long-term neurocognitive function in 60-day-old and 7-day-old rats. Anesthesiology 110: 834-848, 2009.

11. Ocmen E, Derbent A, Micilli SC, Cankurt U, Aksu I, Dayi A, Yilmaz $\mathrm{O}$ and Gokmen N: Erythropoietin diminishes isoflurane-induced apoptosis in rat frontal cortex. Paediatr Anaesth 26: 444-451, 2016

12. Lee BH, Chan JT, Kraeva E, Peterson K and Sall JW: Isoflurane exposure in newborn rats induces long-term cognitive dysfunction in males but not females. Neuropharmacology 83: 9-17, 2014.

13. Li Y, Zeng M, Chen W, Liu C, Wang F, Han X, Zuo Z and Peng S: Dexmedetomidine reduces isoflurane-induced neuroapoptosis partly by preserving PI3K/Akt pathway in the hippocampus of neonatal rats. PLoS One 9: e93639, 2014.

14. Lima SA and Pasquinelli AE: Identification of miRNAs and Their Targets in C. elegans. Adv Exp Med Biol 825: 431-450, 2014.

15. McAdams RM, McPherson RJ, Beyer RP, Bammler TK, Farin FM and Juul SE: Dose-dependent effects of morphine exposure on mRNA and microRNA (miR) expression in hippocampus of stressed neonatal mice. PLoS One 10: e0123047, 2015.

16. Luo T, Yin S, Shi R, Xu C, Wang Y, Cai J, Yue Y and Wu A: miRNA expression profile and involvement of Let-7d-APP in aged rats with isoflurane-induced learning and memory impairment. PLoS One 10: e0119336, 2015

17. Garofalo M, Condorelli G and Croce CM: MicroRNAs in diseases and drug response. Curr Opin Pharmacol 8: 661-667, 2008.

18. Millan MJ: MicroRNA in the regulation and expression of serotonergic transmission in the brain and other tissues. Curr Opin Pharmacol 11: 11-22, 2011.

19. National Research Council (US) Committee for the Update of the Guide for the Care and Use of Laboratory Animals: Guide for the Care and Use of Laboratory Animals. 8th edition. National Academies Press; Washington (DC): 2010

20. Yang C, Zhu B, Ding J and Wang ZG: Isoflurane anesthesia aggravates cognitive impairment in streptozotocin-induced diabetic rats. Int J Clin Exp Med 7: 903-910, 2014.

21. Hummon AB, Lim SR, Difilippantonio MJ and Ried T: Isolation and solubilization of proteins after TRIzol extraction of RNA and DNA from patient material following prolonged storage. Biotechniques 42: 467-470, 2007.

22. Livak KJ and Schmittgen TD: Analysis of relative gene expression data using real-time quantitative PCR and the 2(-Delta Delta C(T)) Method. Methods 25: 402-408, 2001.

23. Wang Y, Kuramitsu Y, Takashima M, Yokoyama Y, Iizuka N, Tamesa T, Sakaida I, Oka M and Nakamura K: Identification of four isoforms of aldolase B down-regulated in hepatocellular carcinoma tissues by means of two-dimensional Western blotting. In Vivo 25: 881-886, 2011.

24. Qin XY, Cheng Y, Murthy SR, Selvaraj P and Loh YP: Carboxypeptidase E- $\Delta \mathrm{N}$, a neuroprotein transiently expressed during development protects embryonic neurons against glutamate neurotoxicity. PLoS One 9: e112996, 2014. 
25. Loepke AW, Istaphanous GK, McAuliffe JJ III, Miles L Hughes EA, McCann JC, Harlow KE, Kurth CD, Williams MT, Vorhees CV and Danzer SC: The effects of neonatal isoflurane exposure in mice on brain cell viability, adult behavior, learning, and memory. Anesth Analg 108: 90-104, 2009.

26. Zhang Y and Xie Z: Anesthetics isoflurane and desflurane differently affect mitochondrial function, learning, and memory. Ann Neurol 72: 630, 2012.

27. Li Y, Liang G, Wang S, Meng Q, Wang Q and Wei H: Effects of fetal exposure to isoflurane on postnatal memory and learning in rats. Neuropharmacology 53: 942-950, 2007.

28. Chen G, Shi J, Hu Z and Hang C: Inhibitory effect on cerebral inflammatory response following traumatic brain injury in rats: A potential neuroprotective mechanism of $\mathrm{N}$-acetylcysteine. Mediators Inflamm 2008: 716458, 2008.

29. Filbert MG and Ballough GPH: Method of reducing brain damage resulting from seizures. US Patent US 6211230 B1. Filed January 19, 2000; issued April 3, 2001.

30. Zhu C, Gao J, Karlsson N, Li Q, Zhang Y, Huang Z, Li H, Kuhn HG and Blomgren K: Isoflurane anesthesia induced persistent, progressive memory impairment, caused a loss of neural stem cells, and reduced neurogenesis in young, but not adult, rodents. J Cereb Blood Flow Metab 30: 1017-1030, 2010.

31. Culley DJ, Baxter MG, Crosby CA, Yukhananov R and Crosby G: Impaired acquisition of spatial memory 2 weeks after isoflurane and isoflurane-nitrous oxide anesthesia in aged rats. Anesth Analg 99: 1393-1397; table of contents, 2004.

32. Mandell JW and Banker GA: A spatial gradient of tau protein phosphorylation in nascent axons. J Neurosci 16: 5727-5740, 1996.

33. Akinlolu RD, Nam M and Wei Q: Competition between fibrillation and induction of vesicle fusion for the membrane-associated 40-residue $\beta$-amyloid peptides. Biochemistry 54: 3416-3419, 2015 .
34. Li C, Liu S, Xing Y and Tao F: The role of hippocampal tau protein phosphorylation in isoflurane-induced cognitive dysfunction in transgenic APP695 mice. Anesth Analg 119: 413-419, 2014.

35. Zhang CY, Mei-Hua P, Liu N, Anestic DO, Hospital TF and University $\mathrm{J}$ : Effects of trehalose on learning and memory impairment induced by isoflurane in APP transgenic mice. Chin J Gerontol, 2015. (in Chinese)

36. Li QQ, Chen ZQ, Cao XX, Xu JD, Xu JW, Chen YY, Wang WJ, ChenQ, Tang F, Liu XP and Xu ZD: Involvement of NF- $\kappa$ B/miR-448 regulatory feedback loop in chemotherapy-induced epithelial-mesenchymal transition of breast cancer cells. Cell Death Differ 18: 16-25, 2011

37. Kyrychenko S, Kyrychenko V, Badr MA, Ikeda Y, Sadoshima J and Shirokova N: Pivotal role of miR-448 in the development of ROS-induced cardiomyopathy. Cardiovase Res 108: 324-334, 2015.

38. Li L, Han W, Gu Y, Qiu S, Lu Q, Jin J, Luo J and Hu X: Honokiol induces a necrotic cell death through the mitochondrial permeability transition pore. Cancer Res 67: 4894-4903, 2007.

39. Varghese J, Khandre NS and Sarin A: Caspase-3 activation is an early event and initiates apoptotic damage in a human leukemia cell line. Apoptosis 8: 363-370, 2003.

40. Noh H, Park C, Park S, Lee YS, Cho SY and Seo H: Prediction of miRNA-mRNA associations in Alzheimer's disease mice using network topology. Bmc Genomics 15: 644, 2014. 